Meta

Journal des traducteurs

Translators' Journal

\title{
Native Language Literacy
}

\section{Philip G. Howard}

Volume 38, numéro 1, mars 1993

La traduction et l'interprétation dans le nord du Canada

Translation and Interpretation in Northen Canada

URI : https://id.erudit.org/iderudit/003144ar

DOI : https://doi.org/10.7202/003144ar

Aller au sommaire du numéro

Éditeur(s)

Les Presses de l'Université de Montréal

ISSN

0026-0452 (imprimé)

1492-1421 (numérique)

Découvrir la revue

Citer cet article

Howard, P. G. (1993). Native Language Literacy. Meta, 38(1), 111-114.

https://doi.org/10.7202/003144ar

\section{Résumé de l'article}

On présente les langues dénés et on explique comment, à l'aide de cours et d'ateliers déformation subventionnés par le gouvernement des Territoires du Nord-Ouest, on apprend à écrire et à lire à des locuteurs natifs de langues qui n'ont pas de tradition d'écriture. On espère ensuite former des traducteurs et des enseignants. 


\title{
NATIVE LANGUAGE LITERACY
}

PHILIP G. HOWARD

Yellowknife, Northwest Territories, Canada

\begin{abstract}
Résumé
On présente les langues dénés et on explique comment, à l'aide de cours et d'ateliers de formation subventionnés par le gouvernement des Territoires du Nord-Ouest, on apprend à écrire et à lire à des locuteurs natifs de langues qui n'ont pas de tradition d'écriture. On espère ensuite former des traducteurs et des enseignants.
\end{abstract}

The term native language literacy here refers to the skills of reading and writing in the aboriginal languages of Canada, and this article focuses on the Dene languages of the Mackenzie Valley of the Northwest Territories. (In this article "DL" will be used to designate the Dene languages.) There are four of these languages - Chipewyan, Dogrib, Gwich'in (Loucheux), and Slavey - but these are sometimes identified as five, since the northern and southern dialects of Slavey, while mutually intelligible, are diverse enough to necessitate some differences in orthography and in spelling conventions.

The Dene did not traditionally develop writing systems for their languages. Nineteenth century missionaries, both Protestant and Roman Catholic, did translations of Bible passages, hymns, catechisms, and other religious materials, using either the English alphabet or the Cree syllabics ${ }^{1}$. While some of these publications are still in existence and can be procured from the Catholic Church and the British and Foreign Bible Society, they did not gain wide usage by the general populace, perhaps partly because neither system of orthography adequately represented the sound systems of the DLs. The one exception in Canada's North was the translation of the Bible and other materials into Gwich'in (known as Loucheux in the Fort McPherson area) in the English orthography, by the Anglican Archdeacon McDonald. These materials are still in use, at least by the older Loucheux speakers.

From the early $1950 \mathrm{~s}$, through the $1960 \mathrm{~s}$, the principles of modern linguistic science were applied by several missionaries and linguists to the DLs, with a view to the development of practical phonemic ${ }^{2}$ alphabets, and this work resulted in the DL writing systems now being used, particularly in the Northwest Territories' Department of Education and by the interpreters in the Department of Culture and Communications. These systems use essentially the Roman orthography (i.e., the English alphabet) with a few added characters to represent sounds not found in English.

Some of these linguists and missionaries had been engaging in the teaching of literacy, but in the early or mid-1970s the Government of the Northwest Territories began seriously to respond to the aboriginal peoples' increasing demands that more emphasis be placed upon their traditional cultures and languages, especially in the field of education. The Department of Education began to organize and sponsor brief workshops in the communities and longer courses in the Teacher Education Program ${ }^{3}$ for the teaching of DL literacy and for the training of DL specialists. Initially it was necessary for the government to contact the linguists and missionaries to develop and teach these courses, but as Dene individuals acquired skills in literacy some of them became language specialists and were engaged by the government to conduct literacy workshops and instruct in literacy courses. The government is currently training a Dene person to be able to instruct in

Meta, XXXVIII, I, 1993 
literacy in all five Dene languages, though as of this writing a professional linguist is required whenever a course includes two or more of the languages. Currently another branch of the government actively involved in training native people in DL literacy is the Language Bureau of the Department of Culture and Communications. When a Dene person is hired by this department as an interpreter, it is necessary that he or she be literate in the DL in order to be able to do written translations as well as oral interpreting. Arctic College now has a program for those training to be interpreter/translators, which program includes a DL literacy course.

Prerequisites for participation in these DL literacy programs are: (a) oral fluency in both English and the native language, and (b) literacy skills in English. Further, an educational level of at least grade 10 is advisable, although some students with only Grade 8 or 9 have become successful in DL literacy. This is not so much a question of the academic level achieved as of the study skills the student has developed.

Fluency in both English and the DL is a requirement on three counts. First, the courses sponsored by both Education and Culture and Communications are designed for people planning to be either teachers or interpreters, who must be able to function in English as well as in the DL. Secondly, since the courses almost invariably include students from more than one DL, the medium of instruction has to be English. And thirdly, persons not fluent in the DL in question seldom have enough understanding of that language to do the work necessary in such a course.

Literacy in English is a requirement because, since English is the medium of instruction, the instructor must prepare in English such materials as instruction sheets, handouts, and assignment sheets.

If a DL literacy course runs for two or three weeks, for example, five days a week and five class hours per day, it will be considered an introductory course. If it runs for four to six weeks, it will include an advanced literacy component into which will be incorporated some basic grammar studies. A student completing an advanced DL literacy course should have achieved accuracy in spelling of at least 80 to 90 percent.

The curriculum and methodology used in these courses have a two-fold focus: introduction to the alphabet of the language, and extensive practice in the application of the alphabet. Becoming acquainted with their alphabets is a comparatively simple process for the students; it involves exposure to it and memorization of it, requiring only a few days. Because these students are already literate in English, it is not a question of their learning to read and write but of their adapting the reading and writing skills to their own languages.

Once the students have become familiar with their orthographies, a number of techniques and strategies are employed to give them the necessary extensive practice in application. It is my observation, in my experience of teaching literacy in five DLs over a period of fifteen years, that the Dene who have become fully competent in the reading and writing of their languages are those who have been much involve in using the written languages. As always, practice makes perfect.

In teaching the alphabets, the instructor presents first the vowels, since in a Dene language, as in English, every syllable must have a vowel. In the South Slavey language, for example, this means ten vowels: $/ \mathrm{a} /, / \mathrm{e} /, \mathrm{i} /, / \mathrm{o} /$, and $/ \mathrm{u} /$ in the oral manner of articulation plus the same five in nasal articulation. The values assigned to these in the DL alphabets are as follows: / a / is as in English "father", /e/ is similar to the vowel sound in "they"; / i / is as in "ski"; / / is like the vowel in "boat" as a French or Italian speaker of English might pronounce it; and / $\mathrm{u} /$ like the vowel in "lute", again as with a French or Italian accent ${ }^{4}$. In order that the students avoid confusing these vowel qualities with those of English, the instructor encourages the students to refer to each vowel, not by its 
English name, but by its Dene sound. Thus /a/ will be called "ah"; / / will be called "ee"; and so on.

In acquainting the students with the consonants, the instructor will first go through the list of those which are essentially identical with the English consonants, such as $/ \mathrm{b} /$, $/ \mathrm{d} /, / \mathrm{f} /, / \mathrm{k} /, / \mathrm{m} /, / \mathrm{t} /$, etc. These usually pose little or no difficulty for the students. Then the consonant sounds not found in English are studied: sounds such as a glottalized / $\mathrm{t}^{\prime} /$ as opposed to the English kind of /t/; or the glottalized / ch'/ versus the / ch/ used in English; or the unvoiced / $t /$ as distinct from the /1/ similar in English. These contrasts require careful attention and practice so that the students develop the skill of quickly and accurately identifying the differences and applying the correct symbol to the sound. Sometimes these differences are minimal so that a student will tend to overlook them until a finely-tuned skill in sound discrimination is developed.

The Dene languages (with the possible exception of some dialects of Gwich'in) are tonal languages employing a two-tone system. What this means is that two words which may seem to the foreigner to be identical, spoken in two different voice-pitch levels, are in fact two totally unrelated words. For example, in South Slavey /gah/translates as "rabbit", but /gáh / (with the voice on a higher pitch) is translated by the English preposition "beside". For reasons not clearly understood, a majority of Dene students in DL literacy encounter their greatest difficulty in learning to accurately identify and mark the tone levels. They easily and automatically hear and understand the differences, but often can't define what the difference is. Some students, on the other hand, quickly and easily learn to discriminate tone contrasts.

Once the students have become familiar with their alphabets, it is incumbent upon the instructor to utilize a wide variety of drills and practice strategies to enable the students to become well-versed in sound discrimination and sound-symbol correspondence. This extensive exposure to the written form of the language is effected by means of reading practice in whole-class or in small-group situations, and by writing practice in many varied modes: dictation by the instructor or by the students taking turns; dictation of syllables, dictation of short words, dictation of longer words, dictation of minimally different grammatical forms, etc.; language experience projects where the student tapes a legend, story, or first-person experience and then transcribes it; memorization of a prepared list of sight words; drills on nonsense syllables designed to focus on the minimal differences between easily confused sounds; preparation and use of flash cards for drills; identification of misspelling done deliberately by the instructor; spelling bees (a competition always enjoyed by the students); and other exercises, all of these presented in varying modes to sustain interest and avoid boredom.

After the students have advanced beyond the beginning stages of a course, classroom lectures may include some very elementary phonology designed to help the students develop understanding and skill in sound discrimination. Speakers of any language, until educated to an awareness, cannot as a rule describe the difference between two similarly produced sounds: for example, speakers of English who have never thought about it probably can't define the phonetic difference between a / $/$ (voiced) and a / $t$ / (unvoiced, aspirated). Basic phonology will enable a student to do this and will sharpen the skill of accurate recognition and representation of a sound.

In a class where there are two or more of the Dene languages involved, there is an added advantage in sound discrimination drills. For example, the Dogrib student will speak a word in that language, and everyone - the Chipewyans, Gwich'ins, and Slaveys, as well as the Dogribs - must write the word. This kind of exercise is done by turns, each of the languages present being used. The sound systems of all five are similar 
enough that the students have to learn only a few extra symbols in addition to their own alphabets.

One difficulty encountered in the administration of these courses is the paucity of reading materials in some of the languages. In Dogrib, North Slavey, and South Slavey the Department of Education and some of the schools have been producing a variety of such materials for some years. But in Gwich'in there is less, and in Chipewyan there is a great scarcity of materials (in the Northwest Territories' dialects) suitable for reading practice. While there are some documents available from the work of the interpreter/translators in the Department of Culture and Communications, the content of these is not such as to elicit interest and motivation on the part of the students. It is to be hoped that individual natives and private native organizations, as well as the government, will become motivated towards contributing to the production of an ever-increasing inventory of DL literary works.

No doubt in any language which has only an oral tradition, the developing of literacy among a substantial percentage of the population is a time-consuming process. This process is well under way in the Dene languages, and one hopes that it will continue unabated.

\section{Notes}

1. This system of writing was developed, and successfully applied to the Cree language, by the English Weslyan Methodist missionary, James Evans, in the 1840s. Subsequently Anglican missionaries found that it worked well for Inuktitut.

2. A phonemic alphabet is one in which each meaningful sound of the language is represented by one symbol only, this symbol being always pronounced in only one way.

3. The TEP in the 1970s was under the Adult Vocational Training Centre, now known as Arctic College.

4. There are some variations of these sounds in Gwich'in which has a larger number of vowels than the other DLs. 